\title{
Laccase pretreatment of wheat straw: effects of the physicochemical characteristics and the kinetics of enzymatic hydrolysis
}

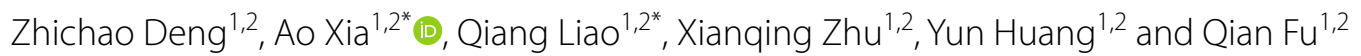

\begin{abstract}
Background: Wheat straw, the most abundant lignocellulosic biomass in China, is rich in cellulose that can be hydrolyzed and then converted into biofuels, such as bioethanol and biohydrogen. However, the accessibility of cellulose and the enzyme activity are greatly reduced in the presence of lignin. This significantly increases the enzyme cost in the saccharification, which hampers industrial production of lignocellulosic biofuels. In this study, a laccase treatment system mediated by 1-hydroxybenzotriazole was employed to modify and degrade lignin to enhance subsequent enzymatic saccharification of wheat straw. A kinetic model considering enzyme adsorption on lignin was proposed to estimate the saccharification performance.

Results: Fourier transform infrared spectroscopy (FTIR) analyses showed that the peak intensity of lignin structure characteristics significantly changed after laccase-mediated system (LMS) treatment. 2D-nuclear magnetic resonance (NMR) analyses indicated that the aromatic ether bonds were cleaved and that guaiacyl (G) was oxidized after LMS treatment. X-ray diffraction (XRD) analyses suggested that the crystallinity of lignocellulose increased due to the partial degradation of lignin. As a result, the nonproductive adsorption of the enzyme on lignin was reduced by $28 \%$, while the reducing sugar yield increased by $26 \%$. A semi-empirical kinetic model was used to estimate the reducing sugar yield, the initial hydrolysis rate $\left(K_{M}\right)$ and deactivation rate coefficient $(a)$ of LMS-pretreated wheat straw were $0.157\left(h^{-1}\right)$ and $0.214\left(h^{-1}\right)$, respectively. The model showed high accuracy (predicting error $\left.<10 \%\right)$ for describing the behavior of laccase-treated wheat straw hydrolysis when the solid loading is $<5 \%$.
\end{abstract}

Conclusions: The adsorption ability of the enzyme to lignin was reduced after LMS pretreatment. Physicochemical analyses showed that the chemical groups of lignin and lignocellulose were changed, with the crystallinity of the lignocellulose increasing after LMS treatment. A semi-empirical kinetic model was proposed to estimate the reducing sugar yield, which showed high accuracy for predicting the hydrolysis performance of laccase-treated wheat straw.

Keywords: Lignocellulose, Laccase treatment, Kinetic model, Saccharification, Wheat straw

\section{Background}

With the rapid increase of global energy demand in recent years, energy shortage has become a common problem in all countries. It has been predicted that the growth of energy demand will come to a peak in 2030, and as a result, the production of easily exploitable fossil

\footnotetext{
*Correspondence: aoxia@cqu.edu.cn; lqzx@cqu.edu.cn

${ }^{1}$ Key Laboratory of Low-grade Energy Utilization Technologies and Systems, Chongqing University, Ministry of Education,

Chongqing 400044, China

Full list of author information is available at the end of the article
}

fuels may not satisfy the need at that time [1]. In addition, climate change and a rise in sea levels, caused by a large amount of greenhouse gases emitted by the combustion of fossil fuels, are also a growing concern of global countries $[2,3]$. The most effective solution to this situation is to aggressively develop renewable energy sources, one such example is biofuels, which have received a great deal of attention and research as a kind of renewable energy [4]. In this context, lignocellulosic biomass has become a sustainable alternative resource of biofuels, such as 
bioethanol and biohydrogen, since it is the most abundant biomass resource on the planet [5].

Lignocellulose is a complex three-dimensional polymer composed of cellulose, hemicellulose and lignin. Cellulose and hemicellulose are polysaccharides that can be hydrolyzed by enzymes into reducing sugars and then utilized [6]. Lignin is a water-insoluble, cross-linked aromatic polymer consisting of three phenyl-propane units linked together by ether and carbon-carbon bonds, which protects cellulose from degradation in nature and makes lignocellulose hard to utilize [7]. Lignin has a higher adsorption capacity for hydrolytic enzymes than carbohydrates, which leads to a decrease in enzyme concentration and reduction of enzyme activity, and it also covers the surface of cellulose to reduce its accessibility [8]. This significantly increases the enzyme cost in the saccharification stage of lignocellulosic biofuel production. Therefore, achieving efficient saccharification is the bottleneck in biofuel production from lignocellulosic materials [9].

Mechanical, physical and chemical pretreatment methods can effectively destroy the natural structure of lignocellulose to make it easy to hydrolyze by enzymes [10]. Nevertheless, such methods require large energy input and equipment maintenance cost. In addition, the byproducts from the pretreatment process would cause inhibition of the subsequent saccharification and fermentation processes [11]. Biological pretreatments have been widely used due to their environmental friendliness, low energy input and mild reaction conditions [12]. Biological pretreatment is based on the reaction of lignindegrading microorganisms, and their secreted enzymes that act upon lignocellulosic biomass to improve the conversion efficiency of polysaccharides in the enzymatic hydrolysis stage [13]. As one kind of ligninolytic enzymes secreted by fungi, laccases can oxidize the phenolic polymer to produce water by using molecular oxygen as the final electron acceptor, which are most likely to achieve large-scale industrial production [14]. Although laccase can oxidize phenolic subunits, it is incapable of oxidizing non-phenolic subunits with a high redox potential in lignin. The mediator is a molecule that transmits electrons between laccase and substrates, such as non-phenols and macromolecular lignin [15]. It enables laccase to oxidize non-phenolic subunits in the lignin. Therefore, laccases are usually combined with a mediator to oxidize lignin in a lignocellulosic biomass.

A few recent literatures have proven that the LMS (laccase mediator system) is sufficiently capable of degrading lignin in lignocellulose materials [16-18]. However, most of the previous studies have focused on the effect of LMS treatment on lignocellulose delignification and the enhancement of reducing sugar yield in the subsequent saccharification process, while key information, such as the change of biomass surface morphology and the evolution of chemical structure and composition in the pretreatment process, was rarely investigated. In addition, the enzymatic hydrolysis kinetics of wheat straw pretreated with laccase has not been proposed, which would lead to an inability to predict the lignocellulosic biomass hydrolysis process after laccase treatment. This is not advantageous for designing a bioreactor with an efficient hydrolysis process.

In the present work, effects of laccase pretreatments on physicochemical characteristics of alkali lignin and wheat straw were comprehensively investigated. Subsequently, the kinetics of enzymatic hydrolysis using pretreated wheat straw were assessed. The aims of this study were to:

- Characterize the effect of LMS pretreatment on the chemical group, the composition and the crystallinity of lignocellulosic feedstocks.

- Assess the characteristics of hydrolytic saccharification of lignocellulose after LMS pretreatment.

- Identify the adsorption characteristics and the kinetic model of enzymes on laccase-treated lignin.

- Propose an enzymatic hydrolysis kinetic model that considers adsorption of enzymes on treated lignin.

\section{Results and discussion}

\section{Characterization of lignocellulosic biomass and lignin} before and after pretreatment

\section{Fourier transform infrared spectroscopy (FTIR) analysis}

FTIR spectra of alkali lignin before and after laccase treatment are shown in Fig. 1a, and the major bands are assigned in Table 1 [19]. The fingerprint region (1600$1000 \mathrm{~cm}^{-1}$ ) in the spectra of alkali lignin significantly changed after laccase and LMS treatment, corresponding to the stretching vibrations of the different groups in lignin [20]. This suggested that the overall structure of alkali lignin had been destroyed, to some extent, after laccase and LMS pretreatment. The spectra of alkali lignin after laccase treatment shows minor changes when compared with the spectra of alkali lignin after LMS treatment. This suggested that the alkali lignin was degraded to a lesser extent when only treated with laccase. After laccase treatments, the stretching vibration peak $\left(1106 \mathrm{~cm}^{-1}\right)$ intensity of alkali lignin decreased, which was derived from an aromatic ring skeleton, indicating that some macromolecular lignin was degraded. The intensity of the peak at $1267 \mathrm{~cm}^{-1}$ changed slightly after laccase pretreatment, which suggested that the carbonyl in guaiacyl was ruptured during the pretreatment. The signal intensity of alkali lignin at $1633 \mathrm{~cm}^{-1}$ increased 

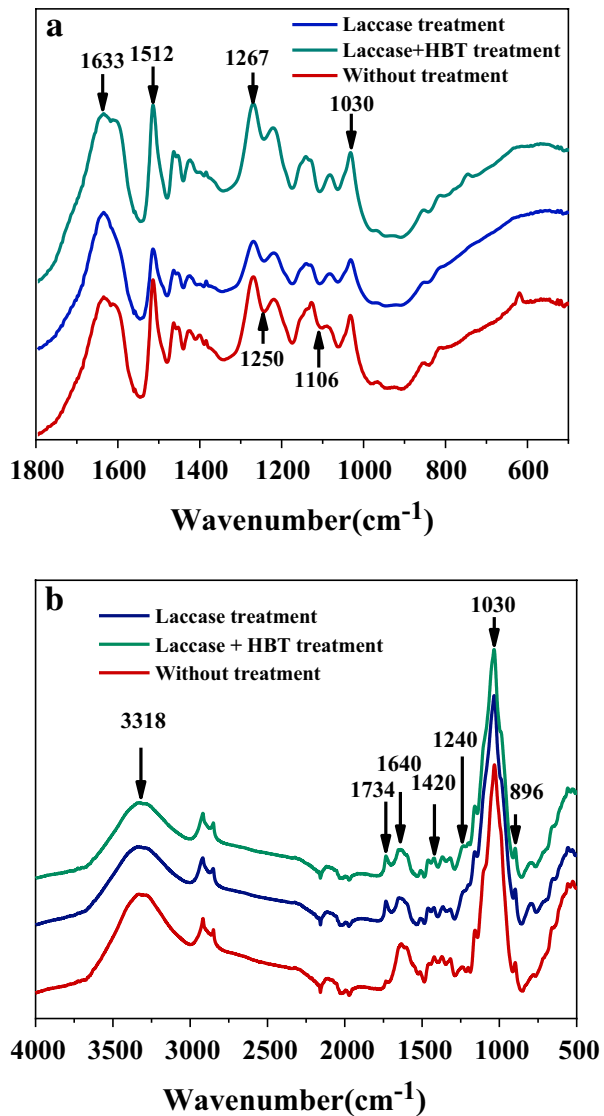

Fig. 1 FTIR spectra of a alkali lignin samples before and after pretreatment, $\mathbf{b}$ lignocellulose samples before and after pretreatment

Table 1 Assignments of FTIR peaks in lignin and lignocellulose samples

\begin{tabular}{|c|c|}
\hline $\begin{array}{l}\text { Wavenumber } \\
\left(\mathrm{cm}^{-1}\right)\end{array}$ & Assignment \\
\hline 3318 & $\begin{array}{l}\text { Stretching vibration of hydroxyl group of hydrogen } \\
\text { bond }\end{array}$ \\
\hline 1734 & $\begin{array}{l}\mathrm{C}=\mathrm{O} \text { stretching of unconjugated ketone, carbonyls, } \\
\text { and ester groups }\end{array}$ \\
\hline 1640,1633 & $\mathrm{C}=\mathrm{C}$ stretching vibration peak in benzene ring \\
\hline 1510 & Ring stretching vibration peak of benzene ring \\
\hline 1420 & $\begin{array}{l}\text { Deformation peak of } \mathrm{C}-\mathrm{H} \text { within vibration plane of } \\
\text { aromatic ring skeleton }\end{array}$ \\
\hline 1267 & The $\mathrm{C}-\mathrm{O}$ stretching of $\mathrm{G}$ type lignin \\
\hline 1250 & $\mathrm{C}-\mathrm{O}$ stretching vibration in phenolic hydroxyl group \\
\hline 1240 & $\begin{array}{l}\text { Stretching vibrations of the in hemicellulose acetyl } \\
\text { esters }\end{array}$ \\
\hline 1106 & $\begin{array}{l}\text { Carbonyl stretching vibrational peaks linked to lignin } \\
\text { and aromatic rings }\end{array}$ \\
\hline 1030 & $\mathrm{C}-\mathrm{O}$ stretching in cellulose and hemicellulose \\
\hline 896 & $\begin{array}{l}\mathrm{C}-\mathrm{O}-\mathrm{C} \text { stretching at } \beta \text {-glucosidic linkages in cellulose } \\
\text { and hemicellulose }\end{array}$ \\
\hline
\end{tabular}

after LMS pretreatment, this indicated the formation of small molecule lignin in the LMS pretreatment [20].

The FTIR spectra of the untreated wheat straw, as well as the laccase-treated sample, are shown in Fig. 1b. The major bands of lignocellulosic sample are assigned in Table 1. The changes of functional groups after pretreatment were mainly concentrated in the absorption peak region $\left(1420 \mathrm{~cm}^{-1}, 1640 \mathrm{~cm}^{-1}\right)$ of lignin structure characteristics, and both of them were reduced, indicating that laccase pretreatments could degrade lignin in wheat straw. The band significantly changed at $1734 \mathrm{~cm}^{-1}$, which is mainly attributed to the $\mathrm{C}=\mathrm{O}$ vibration in acetyl and $p$-coumaroyl groups in lignin, indicating that ester bonds were cleaved in lignin [21]. The adsorption peak at $1240 \mathrm{~cm}^{-1}$ was from stretching vibrations of the in hemicellulose acetyl esters, which significantly changed after laccase and LMS treatment. This indicated that hemicellulose-branched chains were degraded during laccase and LMS treatment. In contrast, the intensity of the peaks at $1030 \mathrm{~cm}^{-1}$ and $896 \mathrm{~cm}^{-1}$, which corresponded to $\mathrm{C}-\mathrm{O}$ stretching in cellulose and hemicellulose and $\mathrm{C}-\mathrm{O}-\mathrm{C}$ stretching at the $\beta$-glucosidic linkages in cellulose and hemicellulose respectively, did not change. This suggested the most of the polysaccharides in the lignocellulose was not degraded during the laccase pretreatment.

\section{D-nuclear magnetic resonance (NMR) analysis}

2D-NMR was used to analyze the different interunit linkages and structural units of the lignin polymers before and after laccase pretreatment (as shown in Fig. 2). The spectrum was divided into three regions: an aromatic ${ }^{13} \mathrm{C}-{ }^{1} \mathrm{H}$ correlation region $\left(\delta_{\mathrm{C}} / \delta_{\mathrm{H}} 50-90 / 3.0-5.5\right)$, a side chain connection ${ }^{13} \mathrm{C}-{ }^{1} \mathrm{H}$ correlation region $\left(\delta_{\mathrm{C}} / \delta_{H}\right.$ 100-150/6.0-8.0) and an aliphatic ${ }^{13} \mathrm{C}-{ }^{1} \mathrm{H}$ correlation region. The first two regions are often the focus of discussion because of their rich structural information. The 2D-NMR spectra of pretreated and untreated alkali lignin are assigned in Table 2 according to previous studies [17].

The side chain connection ${ }^{13} \mathrm{C}-{ }^{1} \mathrm{H}$ correlation region of lignin samples detailed the bond $(\beta-O-4, \beta-\beta)$ between lignin monomers. The methoxyl groups $\left(\mathrm{OCH}_{3}, \delta_{\mathrm{C}} / \delta_{\mathrm{H}}\right.$ $55.4 / 3.72$ ) and $\beta-O-4$ aryl ether (A) are the most significant correlation signals in the side-chain region. The signals at $\delta_{\mathrm{C}} / \delta_{\mathrm{H}} 71.59 / 4.83\left(\mathrm{~A}_{\alpha}\right), \delta_{\mathrm{C}} / \delta_{\mathrm{H}} 84.78 / 4.32\left(\mathrm{~A}_{\beta(\mathrm{G})}\right)$, and $\delta_{\mathrm{C}} / \delta_{\mathrm{H}} 59.5-59.7 / 3.25-3.73\left(\mathrm{~A}_{\gamma}\right)$ belonged to the $\mathrm{C}_{\alpha}-$ $\mathrm{H}_{\alpha}, \mathrm{C}_{\beta}-\mathrm{H}_{\beta}$, and $\mathrm{C}_{\gamma}-\mathrm{H}_{\gamma}$ correlations of the $\beta-O-4^{\prime}$ ether substructures. The signal intensity at $\delta_{\mathrm{C}} / \delta_{\mathrm{H}} 84.78 / 4.32$ $\left(\mathrm{A}_{\beta}\right)$ showed a slight decrease after laccase and LMS pretreatment. This indicated that laccase pretreatment was effective in cleaving aromatic ether bonds in the lignin and destroying the three-dimensional network of lignin. This would increase the accessibility of cellulose to promote enzymatic hydrolysis efficiency. 


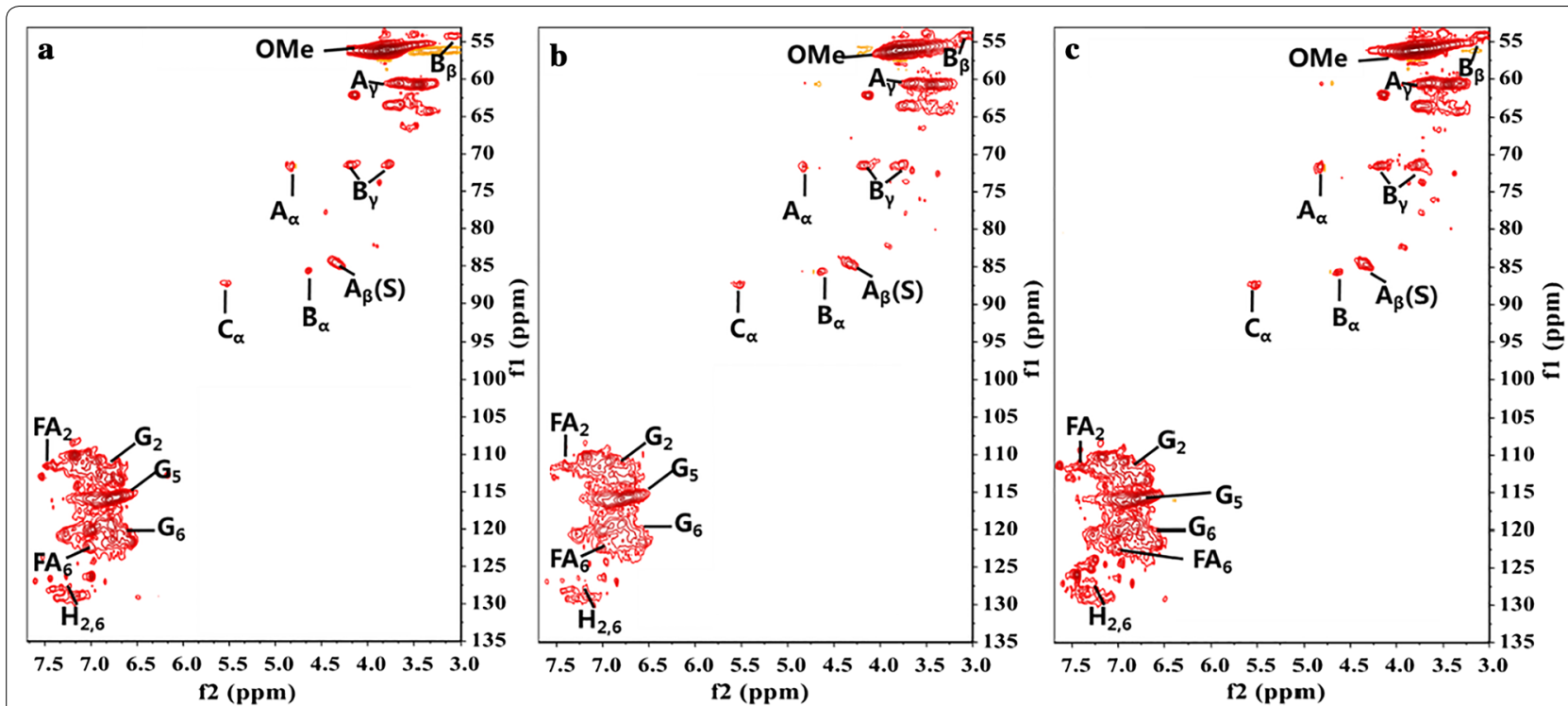

Fig. 2 Heteronuclear single quantum correlation NMR spectra of alkali lignin samples before and after pretreatment. a Untreated alkali lignin, b laccase-pretreated alkali lignin, c LMS-pretreated alkali lignin

Table 2 Assignments of ${ }^{13} \mathrm{C}-{ }^{1} \mathrm{H}$ correlation signals in the HSQC spectrum of lignin samples

\begin{tabular}{|c|c|c|}
\hline Label & $\delta_{\mathrm{C}} / \delta_{\mathrm{H}}(\mathrm{ppm})$ & Assignment \\
\hline $\mathrm{B}_{\beta}$ & $53.4 / 3.11$ & $\mathrm{C}_{\beta}-\mathrm{H}_{\beta}$ in $\beta-\beta$ (resinol) (B) \\
\hline$-\mathrm{OMe}$ & $56.2 / 3.78$ & $\mathrm{C}-\mathrm{H}$ in methoxyls \\
\hline$A_{\gamma}$ & $59.5-59.7 / 3.25-3.73$ & $C_{\gamma}-H_{\gamma}$ in $\beta-O-4$ substructures (A) \\
\hline$B_{\gamma}$ & $71.45 / 4.17-3.78$ & $C_{Y}-H_{Y}$ in $\beta-\beta$ resinol (B) \\
\hline$A_{a}$ & $71.59 / 4.83$ & $\mathrm{C}_{a}-\mathrm{H}_{a}$ in $\beta-O-4$ unit (A) \\
\hline$A_{\beta}$ & $84.78 / 4.32$ & $\begin{array}{l}\mathrm{C}_{\beta}-\mathrm{H}_{\beta} \text { in } \beta-O-4^{\prime} \text { substructures linked to a } \\
\mathrm{G} \text { unit (A) }\end{array}$ \\
\hline $\mathrm{B}_{\mathrm{a}}$ & $85.55 / 4.62$ & $\mathrm{C}_{a}-\mathrm{H}_{a}$ in $\beta-\beta$ resinol (B) \\
\hline$C_{a}$ & $86.6 / 5.49$ & $\begin{array}{l}\mathrm{C}_{a}-\mathrm{H}_{a} \text { in } \beta-5 \text { (phenylcoumaran) substruc- } \\
\text { tures }\end{array}$ \\
\hline $\mathrm{G}_{2}$ & $110.89 / 6.94$ & $\mathrm{C}_{2}-\mathrm{H}_{2}$ in guaiacyl units $(\mathrm{G})$ \\
\hline $\mathrm{FA}_{2}$ & $110.9 / 7.26$ & $\mathrm{C}_{2}-\mathrm{H}_{2}$ in FA \\
\hline $\mathrm{G}_{5}$ & $115.74 / 6.79$ & $\mathrm{C}_{5}-\mathrm{H}_{5}$ in guaiacyl units $(\mathrm{G})$ \\
\hline $\mathrm{G}_{6}$ & $119.33 / 6.8$ & $\mathrm{C}_{6}-\mathrm{H}_{6}$ in guaiacyl units $(\mathrm{G})$ \\
\hline $\mathrm{FA}_{6}$ & $122.6 / 7.03$ & $\mathrm{C}_{6}-\mathrm{H}_{6}$ in FA \\
\hline $\mathrm{H}_{2,6}$ & $127.5 / 7.23$ & $\mathrm{C}_{2,6}-\mathrm{H}_{2,6}$ in $\mathrm{H}$ units $(\mathrm{H})$ \\
\hline
\end{tabular}

The aromatic region mainly reflects the correlation signal of the aromatic ring in alkali lignin. In this region, only signals of the aromatic ring in the guaiacyl $(G)$ and p-hydroxyphenyl $(\mathrm{H})$ structural units can be observed, but the aromatic ring signal of the syringyl (S) structural unit is not observed. This may be due to the low content of syringyl (S) structural units in alkali lignin. The main signal peaks of the guaiacyl unit are located at $\delta_{\mathrm{C}}$ $\delta_{\mathrm{H}} 110.89 / 6.94,115.74 / 6.79$ and $119.33 / 6.8$, which are derived from $\mathrm{C}_{2}-\mathrm{H}_{2}, \mathrm{C}_{5}-\mathrm{H}_{5}$ and $\mathrm{C}_{6}-\mathrm{H}_{6}$, respectively. Interestingly, when compared to untreated $\mathrm{AL}$, the signal of the guaiacyl $(G)$ unit in the pretreated samples showed no significant changes. This phenomenon may be due to the interference of oxidized guaiacyl units.

\section{$X$-ray diffraction (XRD) analysis}

The XRD patterns of the untreated and laccase treated samples are shown in Fig. 3. The crystallinity index of pretreated wheat straw was 27\% (laccase) and $28.57 \%$ (LMS), which were both higher than the untreated raw materials (26\%). The partial degradation of amorphous hemicellulose and removal of lignin during pretreatment led to the increase of the proportion of crystalline

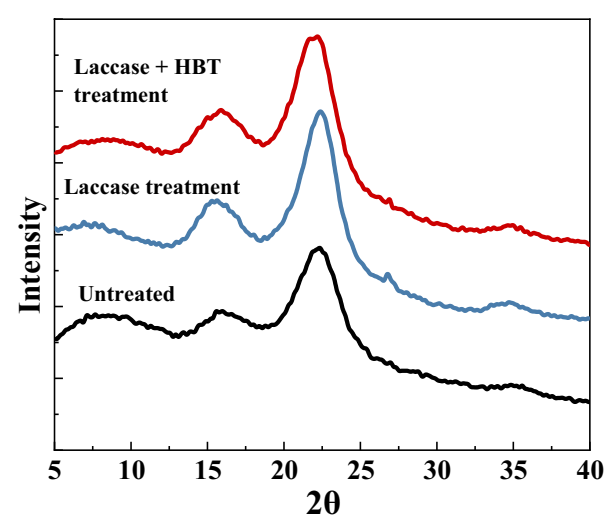

Fig. 3 XRD spectra of lignocellulose samples before and after pretreatment 
cellulose. This resulted in an increase in the crystallinity of the wheat straw residue after laccase pretreatment. A slight increase in crystallinity does not increase the resistance of lignocellulose to enzymatic degradation, while the removal of lignin can reduce the nonproductive adsorption of the enzyme and increase the yield of reducing sugar. In addition, partial removal of hemicellulose and lignin can increase the accessibility of cellulose, which would also increase the yield of reducing sugar. In general, the higher crystallinity of the lignocellulose after laccase pretreatment represents a higher reducing sugar yield.

\section{Elemental analysis}

The element analysis and degree of unsaturation of the untreated and laccase-treated samples are shown in Table 3. The degree of unsaturation of lignocellulose was further reduced by LMS pretreatment, which indicated that the dense structure of lignocellulose was depolymerized during pretreatment, and some of the macromolecular lignin was degraded. The sulfur content of each sample decreased after laccase treatment, which may be due to the dissolution of sulfur in the pretreatment process.

\section{Thermogravimetric (TG) analysis}

Figure 4a shows the TG and differential thermogravimetric (DTG) curves of untreated and laccase-treated lignin and lignocellulose samples. The pyrolysis process of the lignocellulose samples can be divided into four main stages: moisture and very light volatile components that produced during laccase pretreatment removal $\left(<120{ }^{\circ} \mathrm{C}\right)$; degradation of hemicellulose $\left(220-315{ }^{\circ} \mathrm{C}\right)$; lignin and cellulose decomposition $\left(315-400{ }^{\circ} \mathrm{C}\right)$ and lignin degradation $\left(>450{ }^{\circ} \mathrm{C}\right)$. However, alkali lignin only has a dehydration stage and a lignin degradation stage. As indicated in Fig. 4a, the residue char contents of untreated and laccase-treated alkali lignins were $42 \%$, $44 \%$ and $46 \%$, respectively. The DTG curve that corresponded to raw alkali lignin showed a maximum decomposition rate at $385^{\circ} \mathrm{C}$, but the temperature peak of alkali lignin after laccase treatments had a left shift. This suggested that the alkali lignins were converted to small molecule aromatic compounds with poor thermal stability during the laccase treatment process.
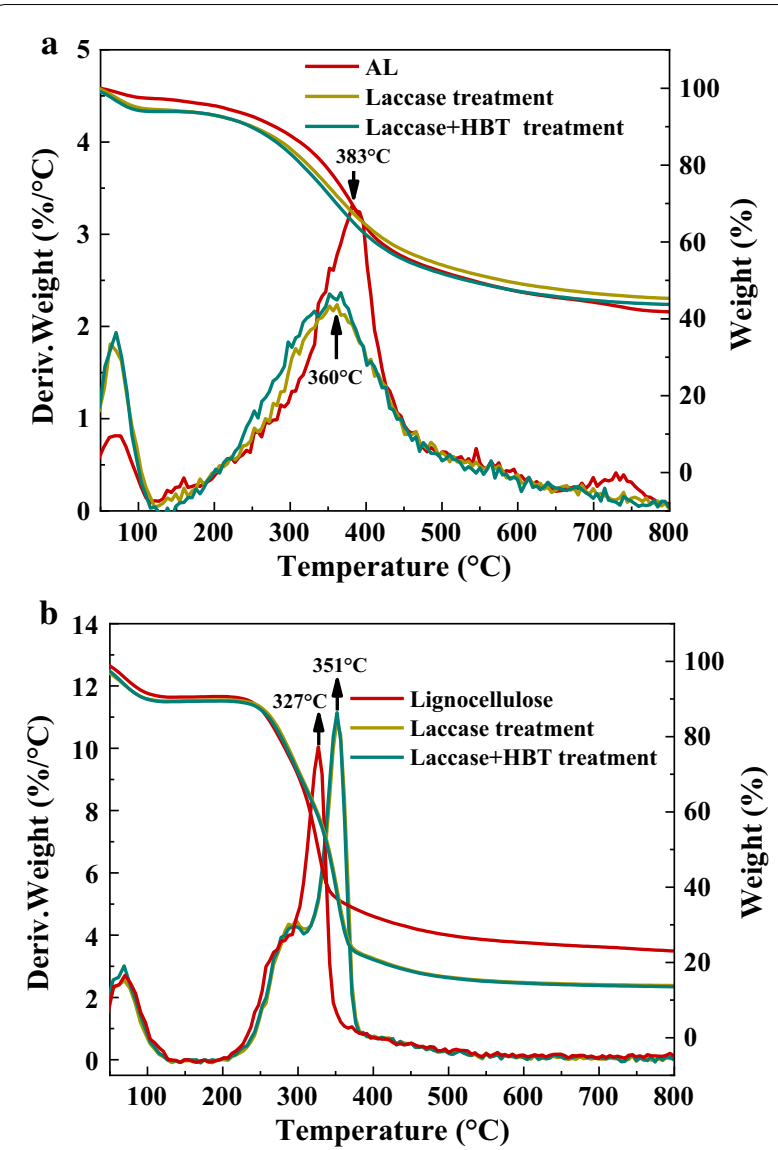

Fig. 4 DTG and TG analysis of a AL before and after pretreatment, $\mathbf{b}$ lignocellulose before and after pretreatment

The DTG curves related to lignocellulose and treated lignocellulose are shown in Fig. 4b. The peak shoulder indicated hemicellulose decomposition, while the main peak indicated cellulose and lignin degradation. Treating with laccase and HBT-shifted hemicellulose and cellulose degradation to a higher temperature $\left(280{ }^{\circ} \mathrm{C}\right.$ and $351{ }^{\circ} \mathrm{C}$, respectively). This is because part of the lignin and the hemicellulose in the wheat straw were degraded, and the removal of hemicellulose and lignin led to increased crystallinity of the raw materials, which gives a higher thermal stability [22].

The residue char contents of lignocellulose decreased significantly after laccase treatment. The

Table 3 Elemental contents of lignocellulose and lignin

\begin{tabular}{|c|c|c|c|c|c|c|c|}
\hline Samples & $C(w t \%)$ & $\mathrm{O}(w t \%)$ & $\mathrm{H}(w t \%)$ & $N(w t \%)$ & S (wt\%) & Formula of $C_{900}$ & $\begin{array}{l}\text { Degree } \\
\text { of unsaturation }\end{array}$ \\
\hline Ligno & 44.66 & 47.7 & 5.47 & 1.336 & 0.83 & $\mathrm{C}_{900} \mathrm{H}_{1323} \mathrm{O}_{721} \mathrm{~N}_{23} \mathrm{~S}_{11}$ & 251 \\
\hline Ligno La & 42.34 & 50.12 & 5.94 & 1.245 & 0.354 & $\mathrm{C}_{900} \mathrm{H}_{1515} \mathrm{O}_{799} \mathrm{~N}_{23} \mathrm{~S}_{3}$ & 155 \\
\hline Ligno La + HBT & 41.23 & 51.64 & 5.53 & 1.322 & 0.277 & $\mathrm{C}_{900} \mathrm{H}_{1449} \mathrm{O}_{845} \mathrm{~N}_{25} \mathrm{~S}_{2}$ & 188 \\
\hline
\end{tabular}




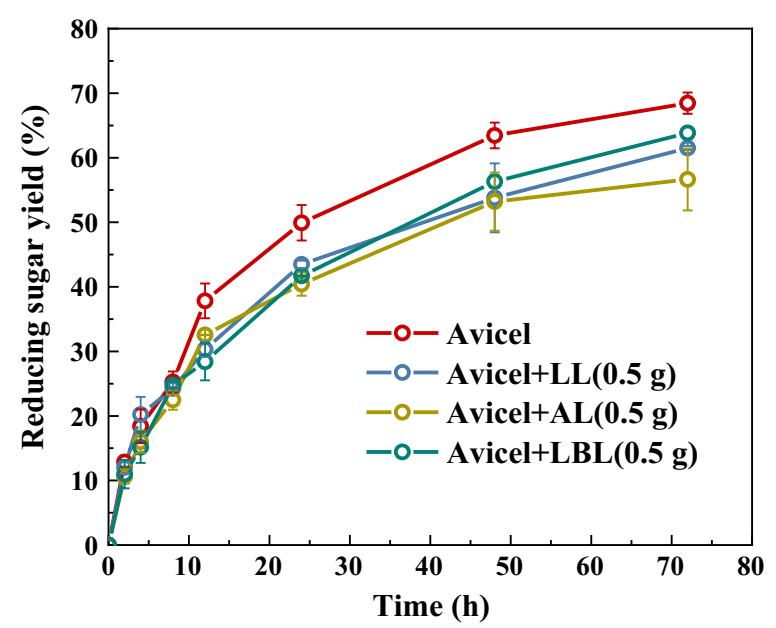

Fig. 5 Effects of modified lignins on glucose yield in enzyme saccharification of Avicel

residual char content is related to the ratio between the guaiacyl and the syringyl unit in the lignin [23]. The larger the proportion of the guaiacyl unit, the more char that remains. The presence of $p$-coumarates acylating the $\gamma-\mathrm{OH}$ of the $\mathrm{S}$ lignin side chains can hamper the action of laccase, therefore, laccase mainly oxidizes the G lignin in the pretreatment and leads to lower residue char content, which has been confirmed by previous $2 \mathrm{D}-\mathrm{NMR}$ results.

\section{The adsorption characteristics and the kinetics model of cocktail enzyme on lignin} Effect of lignin modification on enzymatic hydrolysis of Avicel Figure 5 presents the enzymatic hydrolysis of Avicel with or without the addition of lignins. All lignins had an inhibitory effect on reducing sugar yield. The $72 \mathrm{~h}$ glucan conversion efficiencies with addition of AL (alkali lignin), LL (laccase treated alkali lignin), and LBL (LMS treated alkali lignin) were $53 \%, 58 \%$, and $60 \%$, respectively. The Avicel without lignin addition had a maximum glucose yield at $72 \mathrm{~h}$ of $65 \%$. Although the addition of all lignins had an inhibitory effect on the hydrolysis saccharification process of Avicel, the modified lignins had a less negative effect than untreated alkali lignin. It is due to the adsorption capacity of alkali lignin on hydrolysis enzyme decreased after laccase treatment.

\section{Effects of alkali lignin modification on nonproductive adsorption of enzyme}

Adsorption isotherms were generated using untreated and laccase treated lignins, and they were incubated with different enzyme loadings at $50{ }^{\circ} \mathrm{C}$ for $3 \mathrm{~h}$ (Fig. 6).

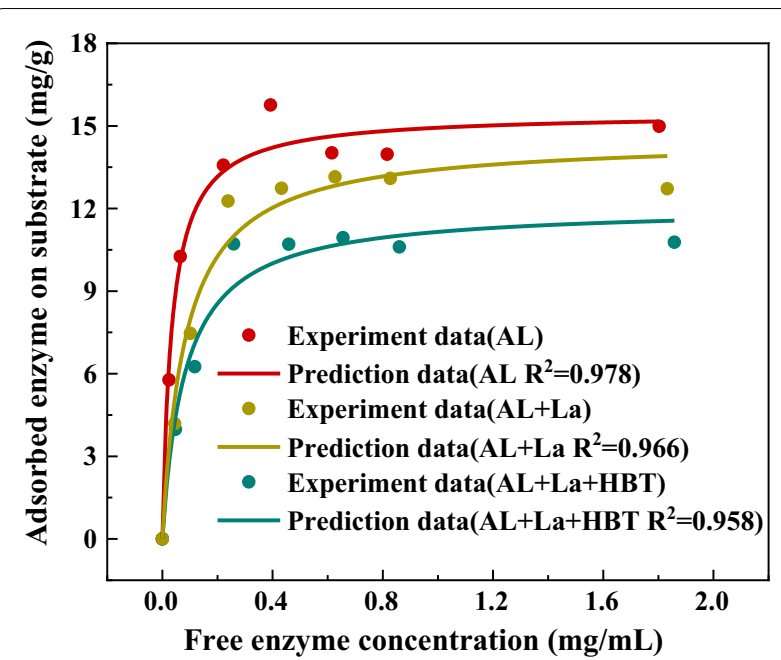

Fig. 6 Cellulase enzyme adsorption on alkali lignin before and after pretreatment

Table 4 Langmuir adsorption isotherm parameters

\begin{tabular}{lll}
\hline Substrate & $\boldsymbol{E}_{\mathbf{m a x}}(\mathbf{m g} \mathbf{g})$ & $\boldsymbol{K}(\mathbf{m L} / \mathbf{m g})$ \\
\hline $\mathrm{AL}$ & 15.45 & 28.55 \\
$\mathrm{AL}+\mathrm{La}$ & 14.54 & 11.97 \\
$\mathrm{AL}+\mathrm{La}+\mathrm{HBT}$ & 12.07 & 12.11 \\
\hline
\end{tabular}

Table 4 shows the adsorption parameters, which were estimated by fitting the enzymatic adsorption data to the Langmuir model. The maximum adsorption capacities $\left(E_{\max }\right)$ of lignins (AL, LL, LBL) were $15.45,14.54$ and $12.07 \mathrm{mg} / \mathrm{g}$ lignin, respectively. Alkali lignin had the strongest adsorption capacity, and could adsorb, approximately, 20-28\% more protein than modified lignins. This is consistent with the results of previous hydrolysis experiments. This may be due to the decrease in polymerization degree of alkali lignin after laccase treatment, which generates more exposed carboxylic groups. This can make the lignin more hydrophilic, which decrease the hydrophobic interaction between lignin and enzyme, thus decreasing the nonproductive binding for cellulase and hemicellulase. Compared with laccase treated with alkali lignin alone, the adsorption capacity of lignin can be reduced by the interaction of the mediator (HBT) and laccase, which is due to the addition of the mediator promoting the alkali lignin to degrade to aromatic compounds with less condensation.

As seen in Table 4, the AL had the highest affinity $(K)$ for enzyme $(28.55 \mathrm{~mL} / \mathrm{mg}$ protein), while LL and LBL had lower affinity for enzyme $(11.97 \mathrm{~mL} / \mathrm{mg}$ protein and $12.11 \mathrm{~mL} / \mathrm{mg}$ protein). The strength of interaction 
between lignin and enzyme was characterized by the coefficient $\left(K_{\mathrm{p}}\right)$, which was calculated using the maximum adsorption capacity multiplied by the Langmuir adsorption constant. The AL had the strongest binding with enzymes, which was about 3 times higher than those of the modified lignins. The results confirmed adsorption capacity of lignin was significantly reduced after lignin modification via LMS treatment, which would be very beneficial for subsequent enzymatic hydrolysis.

\section{The enzymatic hydrolysis of laccase-treated lignocellulose}

Figure $7 \mathrm{a}$ shows the reducing sugar yield of treated and untreated lignocellulose in the enzymatic saccharification process. Compared with the raw wheat straw, laccase pretreatment and LMS pretreatment effectively improved the reducing sugar yield in the enzymatic saccharification process. The maximum reducing sugar yield of $375.9 \mathrm{mg} / \mathrm{g}$ wheat straw was obtained with the LMS pretreatment, which increased by $26 \%$ compared to the raw material. These results suggested that LMS pretreatment can increase the accessibility of cellulose and reduce the unproductive adsorption of lignin on hydrolytic enzymes, which is consistent with the previous characterization. Whereas, laccase pretreated lignocellulose had a lower reducing sugar yield than LMS-pretreated lignocellulose in the enzymatic saccharification process. This indicates that the LMS pretreatment degrades more non-phenolic lignin than the laccase pretreatment, which causes less lignin inhibition on the enzymatic hydrolysis.

The values of $K_{M}$ and $\alpha$ can be determined from the experimental data using nonlinear regression, which is shown in Table 5, and the high $R^{2}$ values $(0.962-0.998)$ showed good fit for the experimental results using the present model, with the predicting error of kinetic model generally less than $10 \%$ (Fig. 8a). $K_{M}$ represents the initial rate of enzymatic hydrolysis, and $\alpha$ is the timedependent decay coefficient that represents the effect of deactivation of the enzyme. Compared with laccasetreated lignocellulose, the untreated lignocellulose had the highest initial reaction rate. This is due to the degradation of lignin in the pretreatment process, which may expose the crystalline cellulose, increasing the difficulty of cellulose degradation by cellulase. This is consistent with the increase of crystallinity of lignocellulose after laccase treatment. Another cause of the degradation, is that a small portion of the easily hydrolyzed hemicellulose in laccase treatment is degraded, which results in the initial hemicellulose hydrolysis rate being relatively slow.
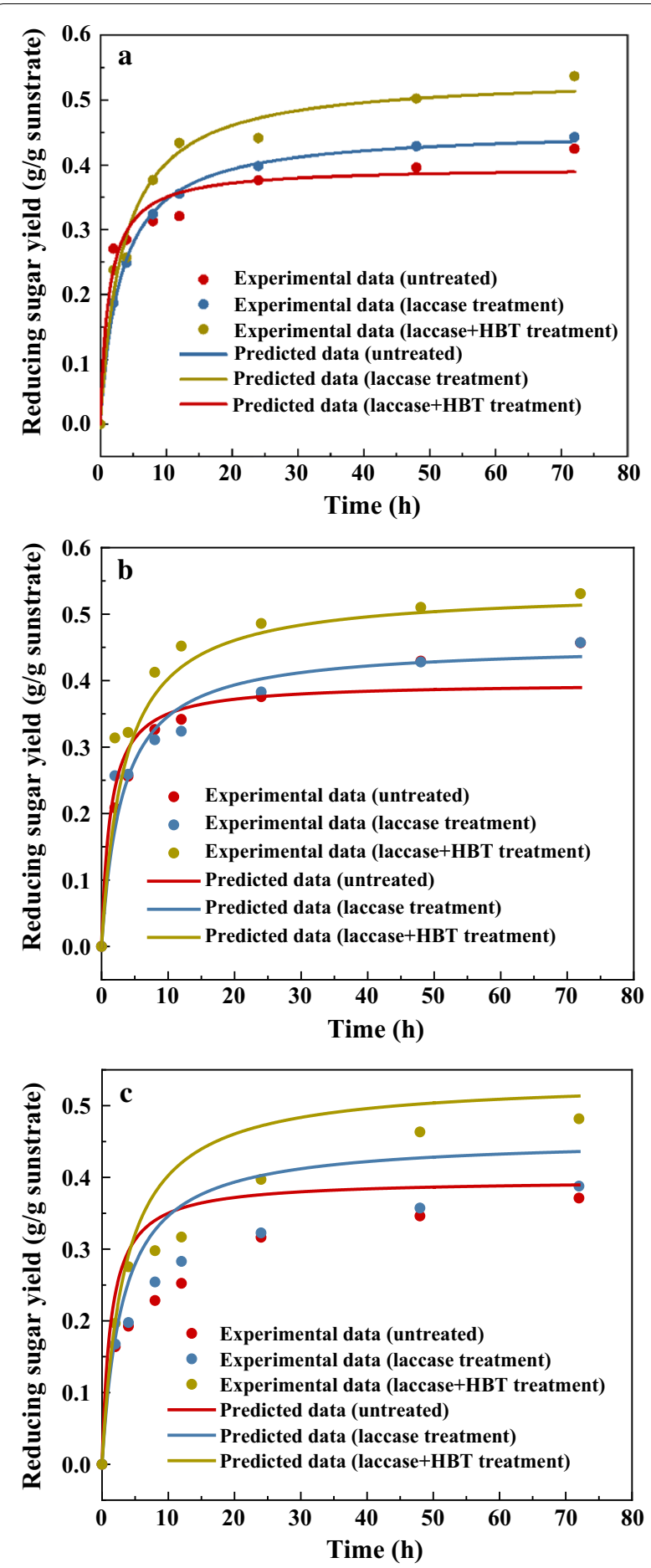

Fig. 7 Enzymatic hydrolysis of lignocellulose a (5\% solid loading) before and after pretreatment, $\mathbf{b}$ ( $2.5 \%$ solid loading) before and after pretreatment, c ( $7.5 \%$ solid loading) before and after pretreatment 
Table 5 Enzymatic hydrolysis kinetic parameters

\begin{tabular}{llll}
\hline Substrate & $\boldsymbol{K}_{\boldsymbol{m}}\left(\mathbf{h}^{\mathbf{- 1}}\right)$ & $\boldsymbol{a}\left(\mathbf{h}^{\mathbf{- 1}}\right)$ & $\boldsymbol{R}^{\mathbf{2}}$ of fitting \\
\hline Untreated & 0.2935 & 0.598 & 0.962 \\
Laccase pretreatment & 0.14263 & 0.2437 & 0.998 \\
LMS pretreatment & 0.157 & 0.214 & 0.980 \\
\hline
\end{tabular}
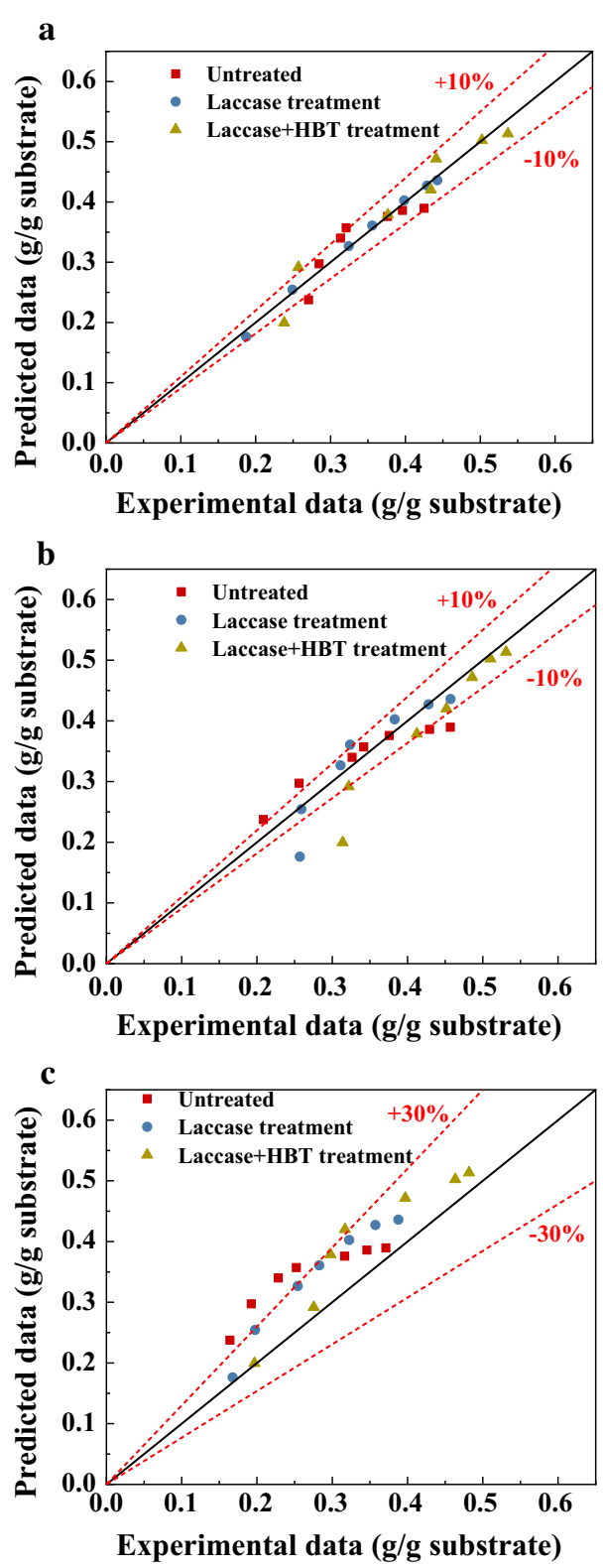

Fig. 8 Comparison of kinetic model predictions with experimental data a $5 \%$ solid loading, b $2.5 \%$ solid loading, c $7.5 \%$ solid loading

\section{Application of the kinetic model to various substrate concentrations}

To verify the applicability of the model to other hydrolysis conditions, experiments were conducted to investigate the effect of different solid loading on the enzymatic hydrolysis of laccase-pretreated and LMS-pretreated lignocellulose. Experimental data of reducing sugar yield were used to validate the proposed enzymatic kinetic model. The fitting results of $2.5 \%$ solid loading are shown in Fig. 7b, and the predicting error of kinetic model of $2.5 \%$ solid loading is shown in Fig. 8b. The predicting error of kinetic model error is generally less than $10 \%$, which suggested that the advanced $\mathrm{M}-\mathrm{M}$ model showed good prediction for LMS-pretreated lignocellulose. However, the untreated lignocellulose had a slightly higher $72 \mathrm{~h}$ reducing yield than the predicted model, which suggested that viscosity is an important factor affecting the hydrolysis reaction of lignocellulose feedstock. The lower the solid concentration of the reaction system, the lower the viscosity, which leads to a higher mass transfer performance, and benefits for the enzymatic hydrolysis of lignocellulose [24].

As shown in Fig. 7c, when the solid content is $7.5 \%$, the prediction values were higher than the experimental values in most cases, and the effect of prediction became worse with increasing time. This may be due to the high viscosity that increased mass transfer resistance during the diffusion of cellulase and hemicellulase to unhydrolyzed lignocellulose, thereby affecting the rate of carbohydrate hydrolysis. As shown in Fig. 8c, the predicting error of kinetic model of treated lignocellulose is less than $30 \%$. On the contrary, the predicting error of kinetic model of untreated lignocellulose exceeded $30 \%$ in many cases. It indicated that the mass transfer had less inhibition on the lignocellulose hydrolysis process of the LMS-pretreated sample than the untreated sample. This may be because the hydrolysis system after LMS pretreatment has a higher free enzyme concentration than the untreated, which would weaken the effects of mass transfer limitations on hydrolysis. The initial mixture viscosity of $7.5 \%$ solid loading is higher than the $2.5 \%$ solid loading of the LMS-pretreated lignocellulose, and it was also found that the $2.5 \%$ solid loading had a higher initial hydrolysis rate than the $7.5 \%$ solid loading. In summary, different solids loading systems have various prediction accuracy. To be better suited to a variety of different reaction conditions, the kinetic model can be modified by adding parameters that affect the mass transfer characteristics of the enzyme to substrate, such as solids and reactor size, in further 
study. The limitation of the model might be that it can only be applied in a solid-liquid system with non-immobilized enzymes, and a more accurate prediction can be attained when more time-dependent data of the yields are provided.

\section{Conclusion}

The effect of LMS treatment on the adsorption ability of the enzyme to alkali lignin has been investigated. Alkali lignin showed the strongest adsorption capacity, which can adsorb approximately $20-28 \%$ more protein than modified lignins. Physiochemical analyses showed that the chemical groups of lignin and lignocellulose were changed, with the crystallinity of the lignocellulose increasing after LMS treatment. The reducing sugar yield during subsequent enzymatic hydrolysis increased by $26 \%$ after LMS treatment. A semi-empirical kinetic model was proposed to estimate the reducing sugar yield, and it showed high accuracy (predicting error $<10 \%$ ) for describing the behavior of laccase treated wheat straw hydrolysis in the low solid loading range. This study provides a prediction approach of the enzymatic hydrolysis of biomass pretreated by laccase, which would be beneficial for optimizing the enzymatic hydrolysis process and for designing the bioreactor.

\section{Methods}

\section{Materials}

The wheat straw used in the experiment was obtained from the Henan province, China. The dried materials (8.7\% moisture) were ground in a grinder and screened with a 40 mesh screen. The composition of the dried wheat straw was $47.97 \%$ cellulose, $20.31 \%$ hemicellulose, $21.18 \%$ lignin and $10.54 \%$ ash. The alkali lignin was purchased from Sigma-Aldrich. All samples were stored in a dryer at room temperature for composition analysis and further use.

\section{Laccase pretreatment}

The treatment using laccase from Trametes versicolor and HBT as redox mediator was employed to degrade or modify the lignin in the wheat straw and the alkali lignin. The treatment trials were carried out in $100 \mathrm{~mL}$ pressurized reactors. $2 \mathrm{~g}$ (dry weight) of the sample were added to the reactors at $5 \%$ solid loading $(\mathrm{w} / \mathrm{w})$ in $0.1 \mathrm{M}$ sodium citrate buffer ( $\mathrm{pH} 4.8)$ under $\mathrm{O}_{2}$ atmosphere (2 bar) and then placed inside a shaker bath maintained at $170 \mathrm{rpm}$ and $50{ }^{\circ} \mathrm{C}$ for $24 \mathrm{~h} \mathrm{[17]}$.

\section{Enzymatic hydrolysis of Avicel}

Enzymatic hydrolysis of Avicel was conducted in a flask containing sodium citrate buffer $(0.1 \mathrm{M}, \mathrm{pH} 4.8)$ for $72 \mathrm{~h}$ at $50{ }^{\circ} \mathrm{C}$. Specifically, the solid substrate loading rate was $5 \%(\mathrm{w} / \mathrm{w})$, and the mixture was stirred in a shake bath at $170 \mathrm{rpm}$. The hydrolysis enzyme used in the experiment was a commercial complex enzyme called Cellic CTec2 (Novozymes, China) with an activity of $200 \mathrm{FPU} / \mathrm{mL}$. The dose of hydrolysis enzyme (SAE0020) was 50 FPU/g substrate. The reducing sugar yield in the hydrolysis process was determined by the DNS method [25].

\section{Enzyme adsorption on lignin}

The adsorption isotherm of enzyme on the alkali lignin, before and after laccase treatment, was studied with different the enzyme protein concentrations, which ranged from 0.1 to $2.0 \mathrm{mg} / \mathrm{mL}$ [26]. Alkali lignin and the enzyme were incubated in a flask that contained $0.1 \mathrm{M}$ sodium citrate buffer $(\mathrm{pH} 4.8)$ at $50^{\circ} \mathrm{C}$ with shaking $(170 \mathrm{rpm})$ for $3 \mathrm{~h}$ to reach equilibrium. The free protein concentration was determined using the Bio-Rad protein assay, which is a Bradford-based colorimetric method, and BSA (SigmaAldrich) was used as a standard [26].

\section{Enzymatic saccharification of wheat straw}

The enzymatic saccharification of untreated or pretreated wheat straw was carried out using the Cellic CTec2. The enzyme loading used in the saccharification process was $50 \mathrm{FPU} / \mathrm{g}$. The hydrolysis was conducted in a $100 \mathrm{~mL}$ flask that contained $38 \mathrm{~mL}$ of sodium citrate buffer $(0.1 \mathrm{M}, \mathrm{pH} 4.8)$ for $72 \mathrm{~h}$ at $50{ }^{\circ} \mathrm{C}$. Specifically, the solid substrate loading ratio was $5 \%(\mathrm{w} / \mathrm{w})$, and the mixture was stirred in a shake bath at $170 \mathrm{rpm}$. The reducing sugar yield in the hydrolysis process was determined by the DNS method.

\section{Chemical structural analysis of the alkali lignin and lignocellulose}

The determination of the chemical composition of raw and pretreated wheat straw was performed according to the National Renewable Energy Laboratory (NREL) [27]. First, $300 \mathrm{mg}$ of wheat straw was mixed with $3 \mathrm{~mL}$ of $72 \%$ (w/w) $\mathrm{H}_{2} \mathrm{SO}_{4}$ at $30{ }^{\circ} \mathrm{C}$ for $60 \mathrm{~min}$ in a water bath, and then the reaction mixture was diluted to $4 \%(\mathrm{w} / \mathrm{w})$ with $84 \mathrm{~mL}$ of deionized water and autoclaved at $121{ }^{\circ} \mathrm{C}$ for $60 \mathrm{~min}$. The lignin content was determined by solid residue, and cellulose and hemicellulose content were determined from monosaccharides in the filtrate using HPLC (High Performance Liquid Chromatography).

FTIR spectroscopic analysis was assessed using a Thermo Scientific Nicolet iN10 FTIR Microscope (Thermo Nicolet Corporation) equipped with a DTGS detector. Scans were conducted at $400-4000 \mathrm{~cm}^{-1}$. Background scanning was performed for correction before data collection. The X-ray diffraction (XRD) method 
was used to determine the crystallinity of the samples by using an X-ray diffractometer (PANalytical Empyrean, Netherlands). The crystallinity index (CrI) was calculated as expressed in Eq. (1).

$$
\mathrm{CrI}=\frac{I_{002}-I_{\mathrm{am}}}{I_{002}} \times 100 \%
$$

$I_{002}$ is the intensity of the (002) peak at approximately $2 \theta=22.5^{\circ}$, and $I_{\mathrm{am}}$ is the peak intensity of the amorphous region at approximately $2 \theta=18.3^{\circ}$ [28].

The HSQC NMR spectra of lignins were detected at $25{ }^{\circ} \mathrm{C}$ using a Bruker AVIII $500 \mathrm{MHz}$ spectrometer (Bruker Biospin, Fallanden, Switzerland). The sample (50 mg) was dissolved in $0.5 \mathrm{~mL}$ dimethyl sulfoxide- $\mathrm{d}_{6}$ and then transferred into an NMR tube. All configurations were referenced to the previous literature [29]. The thermogravimetric properties of the samples were analyzed via an STA409PC TG analyzer (NETZSCH, Germany) at a constant heating rate of $5{ }^{\circ} \mathrm{C} / \mathrm{min}$. The samples were placed in the oven to dry at $105{ }^{\circ} \mathrm{C}$ for $2-3 \mathrm{~h}$ to remove moisture from the samples before TG analysis. A Vario Macro cube element analyzer (Elementar, Germany) was used to determine the content of $\mathrm{C}, \mathrm{H}, \mathrm{N}$ and $\mathrm{S}$ in the samples. The content of oxygen was calculated as $100 \%$ minus the content of the other elements.

\section{Kinetics and mathematical modeling}

Adsorption kinetics model According to the published literature [30], the adsorption of enzyme on lignin can be described well by the following Langmuir equation:

$$
\left[E_{\text {ads }}\right]=\frac{\left[E_{\max }\right] \cdot K \cdot\left[E_{\text {free }}\right]}{1+K \cdot\left[E_{\text {free }}\right]}
$$

$E_{\text {ads }}$ is the amount of enzyme adsorbed on the lignin (mg/g lignin), $E_{\text {free }}$ is the free enzyme concentration $(\mathrm{mg} /$ $\mathrm{mL}$ ) in the suspension, $E_{\max }$ is the maximum enzyme adsorption capacity of lignin ( $\mathrm{mg} / \mathrm{g}$ lignin), and $K$ is the Langmuir adsorption constant ( $\mathrm{mL} / \mathrm{mg}$ enzyme).

Enzymatic hydrolysis kinetic model Enzymatic hydrolysis of wheat straw was conducted in a heterogeneous system. A kinetics model of the enzymatic hydrolysis process was established on the basis of the Michaelis-Menten equation. The advanced $\mathrm{M}-\mathrm{M}$ model assumes that (1) the adsorption of enzymes on the solid substrate is very fast in comparison with the enzymatic reactions; (2) the effect of deactivation of the enzyme is considered as a timedependent decay coefficient; (3) $w$ represents the mass ratio of lignin to cellulose and hemicellulose, and it was determined as 3:7 according to the components analysis in this study; (4) the cellulase and hemicellulase enzymes were assumed to form a combination that can degrade carbohydrates in the lignocellulose to produce reducing sugar; (5) $[E S]$ is at a quasi-steady-state. The advanced $\mathrm{M}-\mathrm{M}$ model is illustrated by the scheme:

$$
E+S \underset{k_{-1}}{\stackrel{k_{1}}{\longrightarrow}} E S \stackrel{k_{2}}{\rightarrow} E+P
$$

S, E, P, and ES represent the substrate (polysaccharide), the complex of free enzyme, and the product, respectively. The reaction rate constants, $k_{1}$ and $k_{2}$, are the forward reaction rates. The reaction rate constant $k_{-1}$ represents the reverse reaction rate. The enzymatic hydrolysis of wheat straw can be expressed by the equation:

$$
\begin{aligned}
& \frac{d[E S]}{\mathrm{d} t}=k_{1}[E][S]-k_{-1}[E S]-k_{2}[E S] \cong 0 \\
& {[E S]=\frac{k_{1}[E][S]}{k_{-1}+k_{2}}} \\
& \frac{d[P]}{\mathrm{d} t}=k_{2}[E S]=\frac{k_{1} k_{2}}{k_{-1}+k_{2}}[E][S]
\end{aligned}
$$

The following equation is based on the fundamental principles of mass conservation:

$$
\left[S_{0}\right]=[S]+[E S]+\lambda[P]
$$

$\left[S_{0}\right]$ represents the initial concentration of the substrate, the constant $\lambda$ represents the average conversion coefficient of cellulose and hemicellulose to reducing sugar, and the value was set as 0.9 for all calculations. Because of the $\mathrm{M}-\mathrm{M}$ model assumption that $[E S] \ll[P]+[S]$, $[E S]$ can be negligible, therefore, Eq. (4) can be simplified as:

$$
\left[S_{0}\right]=[S]+\lambda[P]
$$

After the integration of Eqs. (2)-(8), the dependence of the product concentration by time was obtained:

$$
\frac{d[P]}{\mathrm{d} t}=\frac{k_{1} k_{2}}{k_{-1}+k_{2}}[E]\left(\left[S_{0}\right]-\lambda[P]\right)
$$

Taking the mass balance of the enzyme gives,

$$
\left[E_{0}\right]=[E]+[E S]+\left[E_{a d}\right]+\left[E_{\text {ina }}\right]
$$

$\left[E_{0}\right]$ is the initial concentration of the enzyme, $\left[E_{\mathrm{ad}}\right]$ is the concentration of the enzyme adsorbed on the lignin, and $\left[E_{\text {ina }}\right]$ is the concentration of the inactivated enzyme. Because the effect of deactivation of the enzyme is considered to be a time-dependent decay coefficient $(\alpha)$, the equation for enzyme adsorption and inactivation can be expressed as [31]:

$$
\begin{aligned}
& {\left[E_{\mathrm{ad}}\right]=w\left[S_{0}\right]\left[E_{\mathrm{ads}}\right]} \\
& \frac{d\left[E_{\mathrm{ina}}\right]}{\mathrm{d} t}=k_{\mathrm{ina}}[E]
\end{aligned}
$$




$$
k_{\text {ina }}=\frac{2 \alpha}{1+\alpha t}
$$

Combining Eqs. (11)-(13) gives

$$
\begin{aligned}
& \frac{[P]}{\left[S_{0}\right]}=\left(1-\exp \left(\frac{-\lambda K_{m} t}{1+\alpha t}\right)\right) / \lambda \\
& K_{m}=\frac{k_{1} k_{2}}{k_{-1}+k_{2}}\left(\left[E_{0}\right]-w\left[S_{0}\right]\left[E_{\mathrm{ads}}\right]\right)
\end{aligned}
$$

$K_{m}$ is the initial observed reaction rate, and it can be concluded from the equation that the initial reaction rate is related to the initial enzyme concentration and the enzyme adsorbed on lignin. $K_{m}$ and $\alpha$ were determined from the experimental data using a nonlinear regression by Origin software.

\section{Abbreviations \\ LMS: laccase-mediated system; HBT: 1-hydroxybenzotriazole; FTIR: Fourier transform infrared spectroscopy; 2D-NMR: 2D-nuclear magnetic resonance; XRD: X-ray diffraction; FPU: filter-paper unit; TG: thermogravimetric; DTG: differential thermogravimetric; AL: alkali lignin; LL: laccase-treated lignin; LBL: laccase- and HBT-treated lignin; S: syringyl; G: guaiacyl; H: p-hydroxy phenylpropane.}

\section{Authors' contributions}

ZCD, AX and QL designed the experiment. ZCD carried out the pretreatments and enzymatic saccharification of wheat straw. ZCD and AX wrote the manuscript and analyzed the data. ZCD and QL proposed the enzymatic kinetic model. YH, XQZ and QF contributed to the data analysis and revised the manuscript. All authors read and approved the final manuscript.

\section{Funding}

This work was supported by the State Key Program of National Natural Science of China (No. 51836001), the National Science Foundation for Young Scientists of China (No. 51606021), the Venture \& Innovation Support Program for Chongqing Overseas Returnees (No. cx2017019), the Fundamental Research Funds for the Central Universities (No. 2018CDXYDL0001), and the Young Elite Scientists Sponsorship Program by CAST (2018QNRC001).

\section{Availability of data and materials}

All data generated or analyzed during this study are included in this article.

\section{Ethics approval and consent to participate}

Not applicable.

\section{Consent for publication}

All authors consented on the publication of this work.

\section{Competing interests}

The authors declare that they have no competing interests.

\footnotetext{
Author details

1 Key Laboratory of Low-grade Energy Utilization Technologies and Systems, Chongqing University, Ministry of Education, Chongqing 400044, China. ${ }^{2}$ Institute of Engineering Thermophysics, Chongqing University, Chongqing 400044, China.
}

Received: 13 May 2019 Accepted: 14 June 2019

Published online: 24 June 2019

\section{References}

1. Baeyens J, Kang Q, Appels L, Dewil R, Lv YQ, Tan TW. Challenges and opportunities in improving the production of bio-ethanol. Prog Energy Combust Sci. 2015;47:60-88.

2. Chen KT, Wang JX, Dai YM, Wang PH, Liou CY, Nien CW, Wu JS, Chen CC. Rice husk ash as a catalyst precursor for biodiesel production. J Taiwan Inst Chem Eng. 2013:44:622-9.

3. Nicholls RJ, Cazenave A. Sea-level rise and its impact on coastal zones. Science. 2010:328:1517-20.

4. Bergthorson JM, Thomson MJ. A review of the combustion and emissions properties of advanced transportation biofuels and their impact on existing and future engines. Renew Sustain Energy Rev. 2015;42:1393-417.

5. Chen W, Wu FW, Zhang JH. Potential production of non-food biofuels in China. Renew Energy. 2016;85:939-44.

6. Karimi K, Taherzadeh MJ. A critical review of analytical methods in pretreatment of lignocelluloses: composition, imaging, and crystallinity. Bioresour Technol. 2016;200:1008-18.

7. Sun SL, Huang Y, Sun RC, Tu MB. The strong association of condensed phenolic moieties in isolated lignins with their inhibition of enzymatic hydrolysis. Green Chem. 2016;18:4276-86.

8. Li X, Zheng Y. Lignin-enzyme interaction: mechanism, mitigation approach, modeling, and research prospects. Biotechnol Adv. 2017;35:466-89.

9. Alvira P, Tomas-Pejo E, Ballesteros M, Negro MJ. Pretreatment technologies for an efficient bioethanol production process based on enzymatic hydrolysis: a review. Bioresour Technol. 2010;101:4851-61.

10. Kumar P, Barrett DM, Delwiche MJ, Stroeve P. Methods for pretreatment of lignocellulosic biomass for efficient hydrolysis and biofuel production. Ind Eng Chem Res. 2009;48:3713-29.

11. Phwan CK, Ong HC, Chen WH, Ling TC, Ng EP, Show PL. Overview: comparison of pretreatment technologies and fermentation processes of bioethanol from microalgae. Energy Convers Manage. 2018;173:81-94.

12. Sindhu R, Binod P, Pandey A. Biological pretreatment of lignocellulosic biomass - an overview. Bioresour Technol. 2016;199:76-82.

13. Wan CX, Li YB. Fungal pretreatment of lignocellulosic biomass. Biotechnol Adv. 2012:30:1447-57.

14. Kudanga T, Le Roes-Hill M. Laccase applications in biofuels production: current status and future prospects. Appl Microbiol Biotechnol. 2014;98:6525-42.

15. Munk L, Sitarz AK, Kalyani DC, Mikkelsen JD, Meyer AS. Can laccases catalyze bond cleavage in lignin? Biotechnol Adv. 2015;33:13-24.

16. Rico A, Rencoret J, del Rio JC, Martinez AT, Gutierrez A. Pretreatment with laccase and a phenolic mediator degrades lignin and enhances saccharification of Eucalyptus feedstock. Biotechnol Biofuels. 2014;7:14

17. Rencoret J, Pereira A, del Rio JC, Martinez AT, Gutierrez A. Delignification and saccharification enhancement of sugarcane byproducts by a laccase-based pretreatment. Acs Sust Chem Eng. 2017;5:7145-54

18. Rencoret J, Pereira A, del Rio JC, Martinez AT, Gutierrez A. Laccasemediator pretreatment of wheat straw degrades lignin and improves saccharification. Bioenergy Res. 2016;9:917-30

19. Nobusuke K, Nobuhiko O, Ayumu H, Toyoyuki S, Jun K, Shigenobu H, Yoshinori I, Shigekatsu M. Characteristics of solid residues obtained from hot-compressed-water treatment of woody biomass. Ind Eng Chem Res 2009:48(1):373-9.

20. Ying WJ, Shi ZJ, Yang HY, Xu GF, Zheng ZF, Yang J. Effect of alkaline lignin modification on cellulase-lignin interactions and enzymatic saccharification yield. Biotechnol Biofuels. 2018;11:13.

21. Zhang KJ, Si MY, Liu D, Zhuo SN, Liu MR, Liu H, Yan X, Shi Y. A bionic system with Fenton reaction and bacteria as a model for bioprocessing lignocellulosic biomass. Biotechnol Biofuels. 2018;11:14.

22. Cao S, Aita GM. Enzymatic hydrolysis and ethanol yields of combined surfactant and dilute ammonia treated sugarcane bagasse. Bioresour Technol. 2013;131:357-64

23. Yang XW, Ma FY, Zeng YL, Yu HB, Xu CY, Zhang XY. Structure alteration of lignin in corn stover degraded by white-rot fungus Irpex lacteus CD2. Int Biodeterior Biodegrad. 2010;64:119-23. 
24. Dutta SK, Chakraborty S. Mixing effects on the kinetics and the dynamics of two-phase enzymatic hydrolysis of hemicellulose for biofuel production. Bioresour Technol. 2018;259:276-85.

25. Sun CH, Xia A, Liao Q, Fu Q, Huang Y, Zhu X, Wei PF, Lin RC, Murphy JD. Improving production of volatile fatty acids and hydrogen from microalgae and rice residue: effects of physicochemical characteristics and mix ratios. Appl Energy. 2018;230:1082-92.

26. Zheng Y, Zhang RH, Pan ZL. Investigation of adsorption kinetics and isotherm of cellulase and beta-glucosidase on lignocellulosic substrates. Biomass Bioenergy. 2016;91:1-9.

27. Sluiter JB, Ruiz RO, Scarlata CJ, Sluiter AD, Templeton DW. Compositional analysis of lignocellulosic feedstocks 1 review and description of methods. J Agric Food Chem. 2010;58:9043-53.

28. Park S, Baker JO, Himmel ME, Parilla PA, Johnson DK. Cellulose crystallinity index: measurement techniques and their impact on interpreting cellulase performance. Biotechnol Biofuels. 2010;3:10.
29. Rencoret J Marques G, Gutierrez A, Nieto L, Santos لـ Jimenez-Barbero J Martinez AT, del Rio JC. HSQC-NMR analysis of lignin in woody (Eucalyptus globulus and Picea abies) and non-woody (Agave sisalana) ball-milled plant materials at the gel state 10(th) EWLP, Stockholm, Sweden, August 25-28, 2008. Holzforschung. 2009:63:691-8.

30. Lu XQ, Zheng XJ, Li XZ, Zhao J. Adsorption and mechanism of cellulase enzymes onto lignin isolated from corn stover pretreated with liquid hot water. Biotechnol Biofuels. 2016;9:12.

31. Yang CY, Fang TJ. Kinetics of enzymatic hydrolysis of rice straw by the pretreatment with a bio-based basic ionic liquid under ultrasound. Process Biochem. 2015;50:623-9.

\section{Publisher's Note}

Springer Nature remains neutral with regard to jurisdictional claims in published maps and institutional affiliations.
Ready to submit your research? Choose BMC and benefit from:

- fast, convenient online submission

- thorough peer review by experienced researchers in your field

- rapid publication on acceptance

- support for research data, including large and complex data types

- gold Open Access which fosters wider collaboration and increased citations

- maximum visibility for your research: over $100 \mathrm{M}$ website views per year

At BMC, research is always in progress.

Learn more biomedcentral.com/submissions 